\title{
An Improved Relay Protection Simulation Method - Direction Distance Method
}

\author{
Feng GAO ${ }^{1, a,{ }^{,} \text {, Dong-Hai KUANG }}{ }^{2, b}$ and Xi-Lan $\mathrm{ZHAO}^{3, \mathrm{c}}$ \\ ${ }^{1}$ Beijing Kedong Electric Control System Co. Ltd., Beijing, China \\ ${ }^{2}$ Guangzhou Power Supply Co. Ltd., Guangzhou, China \\ ${ }^{3}$ State Grid Gansu Power Company., Tianshui, China \\ aemail: yl_10000@sina.com \\ ${ }^{*}$ Corresponding author
}

Keywords: Protective relaying, Logic judgment method, Quantitative comparison method, Direction-distance method.

\begin{abstract}
This paper briefly introduces the domestic and foreign status quo of protective relaying simulation technologies. It also summarizes the current problems and obvious drawbacks of three existing methods, which can't meet the requirements of large grid's operation. In this paper, a new protective relaying simulation method, which is direction-distance method, is brought up by considering the principles of direction and distance protection. Based on the topological analysis of logic, the direction-distance method combines the advantages of logic judgment and quantitative comparison methods, and introduces the short circuit power, which makes up the problem that the simple logic method cannot judge the direction protection action. Comparing with quantitative comparison method, the value of the impedance is replaced by the malfunctions equivalent distance, which simplifies the calculation of the protection value. It can realize almost all the malfunctions of complex power grid and do not have to maintain a large number of fixed value parameters. Direction-distance methods combines the strengths of logic judgment method and quantitative comparison method, which is especially suitable for protective relaying simulation.
\end{abstract}

\section{Introduction}

The State Grid Corporation of China is intensifying its management in human, financial as well as resource, and systemizing its planning, construction, operation, recondition and production. The system to promote the construction of power generation operation and management personnel knowledge, technology, skills and other aspects of the new higher requirements [1]. The relay protection simulation simulates the action of the relay protection device in the event of a fault. It is very important to improve the ability of the train operators to deal with abnormal accidents and ensure the safe and stable operation of the power grid.

The traditional relay protection simulation method [2] mainly has the value comparison method, the logic judgment method and the case method. The advantage of the value comparison method is that it does not depend on the fault information and the network topology relation search. The logical relation is simple. The disadvantage is that the precision of the grid model is very high, otherwise it is easy to protect the simulation result from the actual situation. But the protection of the parameters and different operating modes under the maintenance of the value will bring a huge workload. The advantage of the logic judgment method is that the data maintenance amount is small, which is easy to meet the requirement of system protection for quick motion and selectivity. The disadvantage is that when it comes to the need for different voltage level protection, the search program lacks the necessary setting information, Easy to judge the error, resulting in the wrong phenomenon; In addition, the adjacent network between the logical relationship between the lines is not easy to achieve. Case law is the fastest, but the flexibility is poor, basically in the logic and valuation method can not be achieved in the case of a remedy. 
This paper presents a new method of relay protection simulation - direction distance method. The directional distance method is different from the fixed value comparison method and the logic judgment method. It is based on the grid fault calculation and the known fault information as the premise, and combined with the direction protection and distance protection relay protection principle to determine whether the protection action, and then time Set the value for the export criteria, accurate simulation of relay action action.

\section{The Theoretical Basis of Directional Distance Method}

The distance protection [3,4] measures the impedance between the short-circuit points of the protection installation site and compares the set impedance values with the measured values to determine whether or not to take protection action. This protection is only active when $\mathrm{Zj}<\mathrm{Zzd}$, that is, when the tuning impedance $\mathrm{Zzd}$ is greater than or equal to the $\mathrm{Zj}$ measurement impedance. In the complex network of multiple power supply, the principle of distance protection determines the stability of the protection range, the system operation mode changes, the most important thing is to ensure the selectivity of the action. This can be one of the important principles of our distance approach.

The transmission line is an inductive load, and $\Phi \mathrm{d} 1$ is the line impedance angle from the bus to the shorting point. For the protection, when the positive direction $\mathrm{d} 1$ point three-phase short circuit, the short-circuit current İd1 lag behind the bus voltage of a phase angle $\Phi \mathrm{d} 1$, its value is $0^{\circ}<\Phi \mathrm{d} 1<90^{\circ}$; when the opposite three-phase short circuit, Protection provides short-circuit current, then İd2 lag behind the bus voltage phase angle will be $180^{\circ}+\Phi \mathrm{d} 2$. Therefore, the direction of the fault can be used to determine the phase relationship between the current and voltage or the short-circuit power direction of $\Phi d 1$. Directional protection [3,4] requires protection of various faults in the positive direction and no action in the opposite direction. Only the use of directional protection is possible to ensure that more than two power lines in the network connection, the protection of the action between the selectivity. This provides a way for us to further study the direction of distance method.

\section{Fault Equivalent Distance Calculation}

Through the power grid transient calculation [5], we can get short-circuit when the power of the branch direction, do not repeat here, the current problem is to solve the problem of fault distance.

In the realization of the fault distance, the main idea of this paper is to use the fault equivalent distance instead of the impedance value for comparison. The situation shown in the following figure can be used as an example

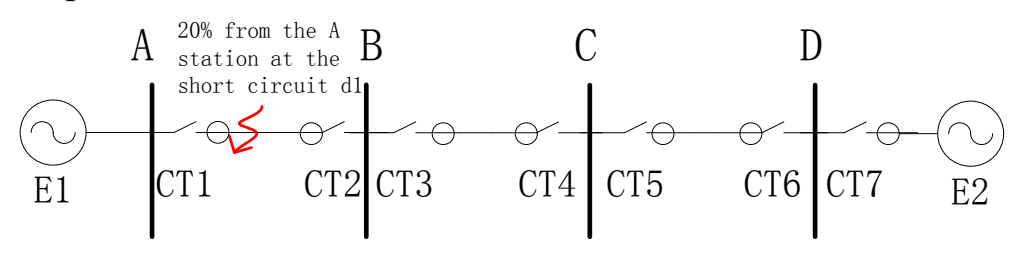

Figure 1 Distance protection calculation network diagram

As shown in Fig. 1, a two-phase short-circuit fault occurs at the AB line by $20 \%$ of the A station. Assuming that the fault distance of the line (ie, the distance between the lines on both sides of the line) is 100 (the value is no unit), the stations A, B, C, D stations can be calculated in the case of known fault information Protected fault equivalent distance.

The equivalent distance of $\mathrm{AB}$ line fault is expressed by $\mathrm{D}(\mathrm{AB})$. From the above information can be seen line fault equivalent distance: $D(A B)=D(B C)=D(C D)=100$

It is thus possible to calculate the equivalent distance of each station to protect the installation to the point of failure as shown in Table 1. 
Table 1 Equivalent Distance Calculation

\begin{tabular}{|l|l|l|}
\hline Distance description (CT distance from the fault point) & $\begin{array}{l}\text { Fault calculation } \\
\text { expression }\end{array}$ & Fault distance \\
\hline $\begin{array}{l}\text { A station protection CT1 fault equivalent distance D } \\
\text { (CT1-d1) }\end{array}$ & $\mathrm{D}(\mathrm{AB})^{*} 10 \%$ & 20 \\
\hline $\begin{array}{l}\text { B station protection CT2 fault equivalent distance D } \\
\text { (CT2-d1) }\end{array}$ & $\mathrm{D}(\mathrm{AB})^{*}(1-10 \%)$ & 80 \\
\hline B station protection CT3 fault equivalent distanceD(CT3-d1) & $\mathrm{D}(\mathrm{CT} 2-\mathrm{d} 1)$ & 80 \\
\hline C station protection CT4 fault equivalent distance D(CT4-d1) & $\mathrm{D}(\mathrm{CT} 2-\mathrm{d} 1)+\mathrm{D}(\mathrm{BC})$ & 180 \\
\hline C station protection CT5 fault equivalent distance D(CT5-d1) & $\mathrm{D}(\mathrm{CT} 2-\mathrm{d} 1)^{+} \mathrm{D}(\mathrm{BC})$ & 180 \\
\hline D station protection CT6 fault equivalent distance D(CT6-d1) & $\begin{array}{l}\mathrm{D}(\mathrm{CT} 2-\mathrm{d} 1)^{+} \\
\mathrm{D}(\mathrm{BC})+\mathrm{D}(\mathrm{CD})\end{array}$ & 280 \\
\hline D station protection CT7 fault equivalent distance D(CT7-d1) & $\begin{array}{l}\mathrm{D}(\mathrm{CT} 2-\mathrm{d} 1)^{+} \\
\mathrm{D}(\mathrm{BC})+\mathrm{D}(\mathrm{CD})\end{array}$ & 280 \\
\hline
\end{tabular}

\section{Implementation of Line Protection}

A variety of protection set value is reflected in two aspects, one with time, the second is the scope of protection. After calculating the fault equivalent distance, you can compare with the value of the fault equivalent distance to determine whether the protection can be activated. Directional distance method of line protection settings as shown in Table 2:

Table 2 Typical line protection settings

\begin{tabular}{|l|l|l|l|}
\hline Specific protection plugin & Time setting (S) & $\begin{array}{l}\text { Fault equivalent } \\
\text { distance setting }\end{array}$ & $\begin{array}{l}\text { Direction setting (1 for the } \\
\text { positive direction, -1 for the } \\
\text { opposite direction, 0 for the } \\
\text { direction of judgment) }\end{array}$ \\
\hline $\begin{array}{l}\text { Longitudinal differential } \\
\text { protection }\end{array}$ & 0 & 100 & 1 \\
\hline Interphase distance & 0 & 80 & 1 \\
\hline Interphase distance II & 0.5 & 180 & 1 \\
\hline Inter-phase distance III & 2.0 & 280 & 1 \\
\hline Ground distance I & 0 & 80 & 1 \\
\hline Ground distance II & 0.5 & 180 & 1 \\
\hline Ground distance III & 2.0 & 280 & 1 \\
\hline
\end{tabular}

Longitudinal differential protection line length, set the line fault equivalent distance of 100 , the time limit is generally $0 \mathrm{~S}$ action, distance protection of the first paragraph can only protect the line length of $80 \%$, the time limit is generally $0 \mathrm{~S}$, fault equivalent The distance is 80 . The scope of protection for paragraph 2 is the full length of the line plus a part of the adjacent line which is the spare part protected by paragraph I and is compatible with the adjacent line distance I, which does not exceed the protection range of the adjacent line distance I The Its action is usually about $0.5 \mathrm{~s}$, the fault equivalent distance of 180 . The third stage is a spare section protected by stages I and II, which protects the line and adjacent lines, plus a part of the next section of the line, so as to match the distance of the adjacent line II, according to the principle of ladder The action time is usually greater than $1 \mathrm{~S}$ and the fault equivalent distance is 280 .

In the short circuit of Figure 1, each station line protection, vertical main protection to meet the line side short-circuit power direction are positive direction, the remaining distance, zero sequence, over-current backup protection only need to meet the side of the short-circuit power for the positive direction Calculated), and the protection fault equivalent distance is less than or equal to the set value can be activated, as shown in Table 3 . 
Table 3 Line motion protection

\begin{tabular}{|l|l|l|l|}
\hline Line protection & $\begin{array}{l}\text { Fault } \\
\text { distance }\end{array}$ & $\begin{array}{l}\text { Power } \\
\text { direction }\end{array}$ & $\begin{array}{l}\text { After the decision to start to determine the } \\
\text { protection }\end{array}$ \\
\hline A station line protection CT1 & 20 & 1 & $\begin{array}{l}\text { Longitudinal differential protection, phase } \\
\text { distance I, phase distance II start }\end{array}$ \\
\hline B station line protection CT2 & 80 & 1 & $\begin{array}{l}\text { Longitudinal differential protection, phase } \\
\text { distance I, phase distance II start }\end{array}$ \\
\hline B station line protection CT3 & 80 & -1 & Unprotected boot \\
\hline C station line protection CT4 & 180 & 1 & Phase distance II start \\
\hline C station line protection CT5 & 180 & -1 & Unprotected boot \\
\hline D station line protection CT6 & 280 & 1 & Phase distance III start \\
\hline D station line protection CT7 & 280 & -1 & Unprotected boot \\
\hline
\end{tabular}

\section{Directional Distance Method}

Based on the topological analysis of the logic method, the vertical distance method is used to make up the short-circuit power direction and make up the pure topology analysis of the single logic method. In the absence of the necessary fault calculation information, the method of directional distance method combined with the logic judgment method and the value comparison method, Can not achieve the direction of the protection of the action problem. Compared with the fixed value comparison method, with the fault equivalent distance to replace the short circuit impedance value of the size of the comparison, which is in accordance with the principle of relay protection set the principle of simplification to protect the value of the calculation.

Direction of the specific implementation of the logic diagram, as shown in Figure 2: 


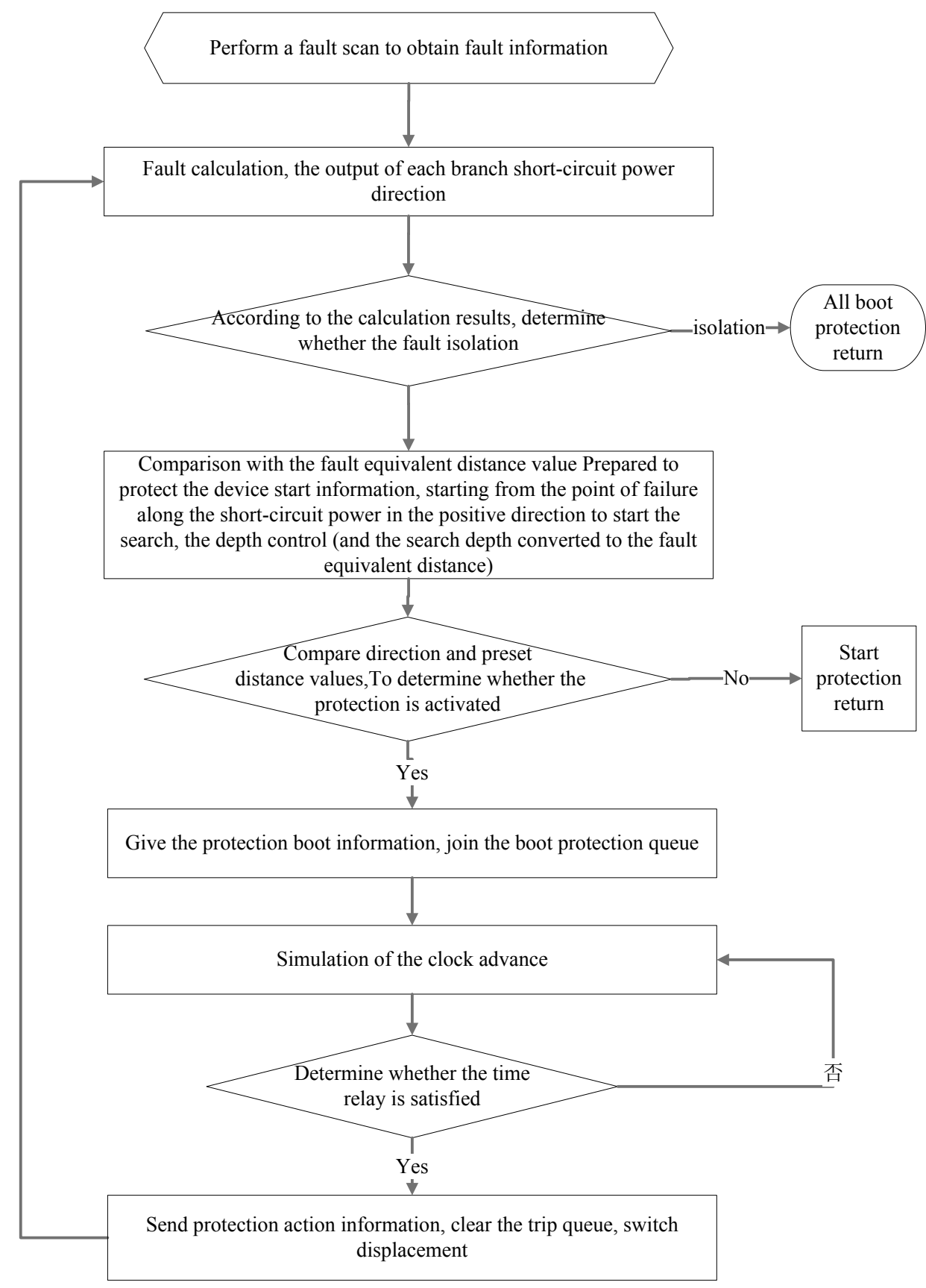

Figure 2 Directional distance method logic block diagram

1) According to the basic information of the fault, the fault calculation obtains the direction of the short circuit power of each branch. The basic information of the fault includes short circuit, short circuit, fault type. And the use of grid fault calculation, the short circuit current and voltage.

2) Based on the combination of power direction, breadth and depth search, the depth-controllable topological analysis algorithm is used to obtain the equivalent fault distance of protection fault.

3) Compare the short-circuit power direction and the fault-equivalent distance to the preset value to determine whether the protection is enabled or not; if the protection is activated, the protection start information is given, and the boot protection queue is added. If this protection is not enabled,

4) simulation of the clock to promote the implementation of the queue to meet the time limit and the action conditions of the protection, the starting signal and the export trip. The topology changes, return to step 1) re-power failure calculation to determine whether the fault has been isolated; if the fault has been isolated all the boot protection reset, the end; if the fault is not isolated, re-iteration until the fault cut. 


\section{Practical System Application}

National University of Technology Institute of operation and control personnel training simulation system around the network of companies to regulate the operation of professional training standards, the secondary substation system for the full range of modeling and simulation, in the relay protection simulation method using the distance method to achieve the right Domestic mainstream relay protection manufacturers, lines, transformers, circuit breakers, bus, capacitor reactors and other common protection device simulation. In the actual simulation system, we use the direction distance method to simulate the protection failure, switch refusal and other complex faults. From the protection action behavior, switch trip results, have achieved the correct protection effect, verify the direction of the distance method of correctness and practicality.

\section{Summary}

Based on the topological analysis of logic, the method of directional distance method combined with logic judgment method and value comparison method is introduced. Based on the topological analysis of logic method, the short circuit power direction is introduced, which makes up the problem that the single logic method can not judge the direction protection action. In contrast to the fixed value comparison method, the value of the impedance is replaced by the fault equivalent distance, which simplifies the calculation of the protection value. This method is accurate for the protection of the action behavior, the protection of the basic value of maintenance, it is particularly suitable for power simulation training system applications.

\section{References}

[1] Lou Huahui. Operational Management Study of Integrated Dispatching and Control Systems of Zhejiang Power Grid [D]. Beijing: North China Electric Power University, 2014.

[2] Jia Ning. Design of the Simulation Module about relay Protection in Dispatcher Training Simulator [D]. Beijing: North China Electric Power University, 2008.

[3] Zhang Baohui, Yin Xianggen. Power System Relay Protection [M]. Beijing: China Electric Power Press, 2010.

[4] He Jia Li, Li Yongli, Dong Xinzhou, etc. Power System Relay Protection Principle (4th Edition) [M]. Beijing: China Electric Power Press, 2010.

[5] Zhai Pei, Yu Qingguang, Li Chengxin et al. Real-Time Electromechanical Transient Simulation of Power System[J]. Power System Technology, 2008,32 (9): 42-45. 